\title{
A EMERGÊNCIA DA ESCOLA
}

LA EMERGENCIA ESCOLAR

THE SCHOOL EMERGENCY

L'URGENCE DE L'ÉCOLE

Miriam Fernandes Muramoto ${ }^{1}$

GONDRA, José Gonçalves. A Emergência da Escola. São Paulo: Cortez, 2018.

A emergência da escola, o modo como surgiu e se constituiu o modelo escolar que se tornou dominante nos últimos 150 anos, é o problema central do livro escrito por José G. Gondra, lançado em 2018. Com comentários de António Nóvoa, Margareth Rago e apresentação de Diana Vidal, o livro publicado pela Cortez Editora, nos mostra a maneira pela qual se deu a emergência da escola no período imperial do Brasil.

${ }^{1}$ Universidade de São Paulo (USP), São Paulo/SP, Brasil. 
O autor, pesquisador na área, possui larga experiência. É professor titular da Universidade do Estado do Rio de Janeiro (UERJ) e pesquisador da FAPERJ, entre outras qualificações. É docente há mais de trinta anos, tendo atuado na educação básica e, atualmente, no ensino superior. Entre diversas outras obras, destaca-se no seu labor autoral as que publicou pela Cortez, com Alessandra Schueler, Educação, Poder e Sociedade no Império Brasileiro e pela EDUERJ, Artes de Civilizar, medicina, higiene e educação escolar na Corte Imperial. Em 2018 escreveu "A emergência da escola" resultante do seu concurso para professor titular, em parceria com o seu grupo de pesquisa realizada no âmbito do Núcleo de Ensino e Pesquisa em História da Educação da Universidade do Estado do Rio de Janeiro (NEPHE/UERJ), integrado pelos pesquisadores Marina Natsume Uekane, Giselle Baptista Teixeira, Daniel Cavalcanti de Albuquerque Lemos, Pedro Paulo Hausmann Tavares, Pollyanna Gomes Pinho, Inára Garcia e Angélica Borges, citados como coautores do texto. Pollyana Gomes Pinho junta-se ao autor na escrita do capítulo IV.

Nas palavras de Nóvoa, essa inserção no campo da história da educação, aliada ao estado atual da historiografia educacional no Brasil, justificam o tipo de produção realizada, uma reflexão útil e necessária para os dias de hoje quando a escola vive uma situação crítica, seja pela incapacidade de cumprir a promessa de ofertar uma educação de qualidade a todas as crianças, seja pela inevitabilidade da sua transformação.

A obra escrita em 261 páginas está dividida em 5 capítulos. O primeiro deles é intitulado "O governo das multidões"; o segundo, "A instrução reformada"; o terceiro trata do "Governo dos professores"; o quarto do "Governo das aulas"; e, finalizando com o quinto capítulo que tem como título "Um governo para si". Para deleite dos leitores, o autor traz anexada a documentação levantada pela equipe no Arquivo Geral da Cidade do Rio de Janeiro e no Arquivo Nacional. Trata-se do Regulamento da Província do Espírito Santo (1848), o Regulamento da Província do Rio de Janeiro (1849), o Regulamento da Corte (1854), Cartas do professor da roça (1864) e Manifesto 
dos Professores Públicos da Instrução Primária da Corte (1871), disponibilizando assim um rico material para os próximos historiadores da educação.

No dizer conhecedor de Diana Vidal, na sua apresentação à obra:

Este livro sobre o governo dos vivos apresenta-se (...) como poliédrico. Se a sequência dos capítulos indica um percurso, a contiguidade das partes permite o trânsito entre as análises. O encontro das vertentes assegura a harmonia dos sentidos. A rotação da figura não desorganiza a escrita. Ao contrário, exibe a coesão da sua arquitetura. (GONDRA, 2018, p. 9)

Logo no início do primeiro capítulo, o autor esclarece a questão central do seu trabalho:

Governar, moralizar, disciplinar, higienizar e civilizar o povo, em muitos momentos, no Brasil e no exterior, estabeleceu a instrução e a escola como fórmula que condensava esses ambiciosos objetivos. Neste sentido, uma cadeia de causalidades foi sendo produzida, instalando, no ponto inicial, a escolarização, tida então como fundamento e critério para se bem governar as multidões. (GONDRA, 2018, p. 12)

Esse é o foco da sua obra. Dele emana a procura dos textos que são produzidos nos momentos das, diríamos, quase constantes reformas educacionais que pautaram a Instrução Pública brasileira ao longo do século XIX. Estes textos informam discursos fecundos em torno de como instruir, de como educar, de como, no dizer de Foucault, governar as multidões. Como afirma o autor:

Um dos momentos em que a proliferação dos discursos vem sendo evidenciada, nas mais variadas áreas e campos disciplinares, constituiu-se precisamente nos períodos em que se torna perceptível a exaustão dos esquemas postos em funcionamento, criando as condições de possibilidade para o aparecimento da necessidade e, 
consequentemente, da legitimidade de reformas, revestidas com a "pretensão de conferir uma melhor forma" àquilo que é constituído em objeto da mesma, convertendo-a em um "fato providencial, uma etapa capital no progresso indefinido da Humanidade”.(GONDRA, 2018, p. 12)

Recorrendo a Foucault, Gondra refere e utiliza a ideia do poliedro de inteligibilidade, com faces sempre em crescimento numérico, bem como em reposicionamento, para enfocar os discursos reformadores. Tendo como base este enfoque teórico, o autor parte para a análise dos processos multifacetados traçados em torno da construção e aplicação da Reforma Couto de 1854, no Município da Corte.

Neste contexto, Gondra focaliza, no segundo capítulo da obra, o Regulamento das Escolas de Primeiras Letras, implementado por Luiz Pedreira Couto Ferraz, em 1854, no Município da Corte, partindo da ação do legislador no período imediatamente anterior da implementação reformista nas Províncias do Espírito Santo e do Rio de Janeiro, respectivamente nos anos de 1848 e 1849. Há uma emersão na descrição dos saberes, tempos, espaços, sujeitos e métodos perceptíveis naquele modelo de instrução. Estes processos reformadores visavam levar a instrução brasileira ao que era entendido como modernidade educativa, tomando como exemplo o que então sucedia na Europa e nos Estados Unidos. No dizer de Gondra, nos três Regulamentos,

(...) procura-se forjar um modelo de escola moderna, o que implicou em prescrições voltadas para aspectos tais como a estrutura administrativa, idade e condição dos alunos, raio de ação das escolas e saberes a serem ensinados, a questão dos métodos e dos problemas de formação e recrutamento de professores, arquitetura escolar, distribuição de tempo, regime de inspeção das escolas públicas e particulares, gratuidade e obrigatoriedade escolar.(GONDRA, 2018, p. 20)

O autor avança para o estudo detalhado da implantação daquilo a que ele intitula de "mecanismos de auto regulação" na construção e 
desenvolvimento do governo da Escola. Para isto, aborda um conjunto de aspectos que envolvem desde o discurso médico-higiênico da época até as prescrições quanto à idade, gênero, regras sociais, moralidade, uso do método simultâneo, entre outros, dirigidas aos futuros professores.

O submetimento da rede privada a um controle do Estado é justificável no interior de um projeto mais alargado de parte dos homens do governo que, à luz do que vai, segundo eles, se processando no exterior, associam o alcance do grau de civilizado à existência de uma rede escolar mais uniforme. Nesse tipo de investimento material e imaginário, à escola passa a ser atribuída a função de alavancar a excolônia à condição de uma nação moderna e polida, tornando-se compreensível que a força do Estado também passasse a atuar sobre a malha das escolas criadas e mantidas pela iniciativa privada. (GONDRA, 2018, p. 29)

Os professores são o objeto privilegiado do terceiro capítulo. Nele o autor elucida de forma detalhada, ancorada em estudo documental arquivístico e bibliográfico, o processo de profissionalização da docência na Corte Imperial, em três aspectos essenciais: formação, seleção/exame e ofício.

Gondra traça o quadro da formação docente antes da Reforma Couto, partindo do aparecimento, em 1835, da Escola Normal do Rio de Janeiro, até a sua extinção em 1851. Em seguida, aborda a emergência de um modelo de formação ancorado na criação de um corpo de professores adjuntos, formado nas escolas de primeiras letras, modelo esse em vigor até 1879 .

A maneira como esse modelo de formação se constituiu demonstra que aos professores primários bastaria conhecer as noções de primeiras letras, acrescido de um certo domínio do método utilizado nas escolas sem , no entanto, abandonar a questão da moralidade, vista como um requisito central e decisivo para que os candidatos fossem considerados qualificados para o exercício do magistério. (GONDRA, 2018, p. 38)

Gondra detém-se, em seguida, no estudo do processo da criação, em 
1880, da Escola Normal da Corte, bem como de seu funcionamento. Analisa, entre outros temas, o perfil etário dos alunos, o currículo, chamando a atenção para algumas dificuldades e incongruências na sua aplicação, o tipo de professores que foi sendo recrutado para aí lecionar, os exames, a sua exigência e o elevado número de reprovações.

Partindo do estipulado no Regulamento de 17 de fevereiro de 1854, o autor visou apurar quem se apresentava como candidato ao processo de seleção para professor, cotejando esse desejo com as exigências impostas. Mostra a importância atribuída à idoneidade moral dos candidatos, suas habilitações e à prática docente anterior. E são visíveis na documentação compulsada as tentativas de muitos candidatos em burlarem o sistema, ou, pelo menos, serem isentos de alguns passos exigidos regularmentemente.

Gondra desocultou as tensões existentes nos processos de organização, realização e divulgação escrita dos resultados das Conferências Pedagógicas, mostrando como, na esteira do produzido por Foucault em A Arqueologia do Saber, a verdade das narrativas não corresponde muitas vezes à realidade dos fatos, bem como a existência de duas ou mais linhas de narrativa sobre os mesmos fatos. Ele ensina aos investigadores das práticas docentes em contexto de sala de aula que os documentos se revelam sempre rarefeitos.

O historiador procurou analisar, num constante cruzamento com as outras fontes referidas, os manuais publicados e utilizados entre os anos de 1854 a 1877. O seu guia teórico neste contexto, foi novamente, uma afirmação de Foucault: "buscamos nos aproximar do entendimento de Foucault (1995) de que a unidade dos livros é variável e relativa e que, submetida a um questionamento, perde sua evidência, não se indicando a si mesmo, e só se construindo a partir de um campo complexo de discursos" (p. 89).

Numa primeira fase, vemos o processo de análise e censura dos livros escolares que, sob o controle do Conselho de Instrução Pública, levava à autorização da sua possível adoção por parte das escolas públicas ou particulares. Em seguida, a forma como a Imprensa Pedagógica analisava e 
criticava estas produções manualísticas e didáticas.

No capítulo IV, O Governo das aulas, Gondra inclui um tópico - Saberes prescritos - que indica ter sido escrito a quatro mãos, com Pollyanna Gomes Pinho, no qual procura analisar, ainda no contexto da Reforma Couto de 1854, as mudanças no Ensino Secundário na Corte. Salvo melhor opinião, parece-nos que este poderia ter-se constituído num capítulo específico da obra. Num número reduzido de páginas é feito o histórico deste nível de Ensino, desde as reformas pombalinas à década de 1850. O autor avança com a tese, bem fundamentada, de que as classes populares estavam propositadamente arredadas do acesso ao Ensino Secundário, o que era essencial para a reprodução das hierarquias sociais.

Intitulado Um Governo para Si, o quinto e último capítulo da obra falanos dos professores e das suas iniciativas. Esta é a base para o lançamento de uma parte da obra que demonstra a realização de uma pesquisa exaustiva e se revela marcadamente original. Nele são analisados detalhadamente manifestos de professores, as suas razões, o seu debate, a sua recepção entre a dita opinião pública e as autoridades, e os seus efeitos, quando eles se revelaram significativos. No dizer final dos dois autores deste capítulo:

(...) a reflexão acerca dos manifestos fornece possibilidades para se pensar as condições de surgimento do movimento de professores, das suas formas de organizações, reivindicação e atuação. Assim, a reunião, publicação e republicação de documentos que testemunham a luta comum funcionam como uma estratégia dos professores de forma a condensar caminhos por eles percorridos em busca de reconhecimento, melhores condições de trabalho e melhor remuneração para a classe. (GONDRA, 2018, p. 138)

Numa conclusão, plena de um aparato teórico amplamente consolidado, Gondra se volta, ainda uma vez, ao conceito foucaultiano de governamentalidade aplicado ao caso específico da Escola no momento histórico em que ela emergiu e consolidou, por meio da construção de edifícios 
escolares, da formação sistematizada dos professores, da organização até ao mais ínfimos pormenores dos vários níveis de Ensino, servindo ao insidioso escopo de contribuir decisivamente para o governo das multidões.

Penso que devemos terminar remetendo para a forma como Gondra, no seu parágrafo final, faz a indispensável transposição do período que estudou, para todos os outros tempos, muito particularmente para o hoje em que vivemos:

(...) é importante observar o poder que procura modelar a escola, sendo igualmente necessário observar a força da escola e de seus agentes. Nesta tensão é que, imagino, podemos pensar o processo de emergência e dos impactos da escola na organização de determinados projetos sociais e a escola como um dos seus (d)efeitos. Deste modo, não é possível pensar o dispositivo escolar como um "de fora" do mundo social e das disputas políticas em torno dos projetos para os sujeitos e para a vida comum. É com eles que o aparato escolar dialoga, nos quais se inscreve, é forjado e ajuda a definir seus contornos, alcances e limites. É, pois, na chave das articulações entre disciplina e biopolítica que as formas escolares se constituem e são reconfiguradas nos vários presentes. (GONDRA, 2018, p. 143)

Em suma, esta obra de Gondra assume-se como uma pedra relevante no edifício que constitui a História da Educação brasileira. Escrito por um autor com obra assinalável, este livro revela-se de conhecimento e estudo essencial para todos aqueles que trabalhem ou se interessem sobre a construção educacional e instrucional do Brasil novecentista.

\section{REFERÊNCIAS}

FOUCAULT, Michel. Vigiar e Punir: nascimento de uma prisão. Petrópolis. Vozes, 1987.

FOUCAULT, Michel. Microfísica do poder. 7. ed. Tradução de Roberto Machado. Rio de Janeiro: Graal, 1988. 
FOUCAULT. Michel. Arqueologia do saber. Rio de Janeiro: Forense, 1995.

GONDRA, José G. A emergência da escola. São Paulo: Cortez, 2018.

MIRIAM FERNANDES MURAMOTO é doutoranda em História da Educação pela Universidade de São Paulo, sob a orientação da professora Dra. Carlota Boto. Mestre em Educação pela Universidade de São Paulo - USP (2016) sob orientação da Profa. Dra. Maurilane de Souza Biccas. Graduada em Pedagogia pela Universidade de São Paulo - USP (2010). Membra do Grupo de estudos sobre história e Religião (GEHER), dedicando-me a estudar os colégios confessionais, tema que me iniciei nas pesquisas científicas, levando em consideração a linha de pesquisa do grupo: educação, história e religião. Participa do NIEPHE - Núcleo Interdisciplinar de Estudos e Pesquisas em História da Educação, coordenado pelas professoras Diana Vidal e Maurilane Biccas. Já pesquisou sobre as iniciativas católicas na educação paulista no início do século $X X$; e, no momento desenvolve uma pesquisa sobre as práticas educativas (décadas 1900 - 1930) na interface educação, higiene e filantropia.

E-mail: miriam.usp@hotmail.com

(D) http://orcid.org/0000-0002-9938-1776

Recebido em: 05 de agosto de 2019

Aprovado em: 12 de novembro de 2019

Revista História da Educação - RHE

Associação Sul-Rio-Grandense de Pesquisadores em História da Educação - Asphe

Artigo de acesso aberto distribuído nos termos de licença Creative Commons. 